\title{
Medicare and the 3-Inpatient Midnight Requirement: A Statute in Need of Modernization
}

\author{
Ann M. Sheehy, MD, MS ${ }^{*}$, Representative Joe Courtney (D-CT) ${ }^{2}$
}

1 University of Wisconsin School of Medicine and Public Health, Department of Medicine, Division of Hospital Medicine, Madison, Wisconsin; 2United States House of Representatives, representing Connecticut.

On July 30, 1965, Lyndon B. Johnson signed H.R. 6675 into law, establishing Medicare and Medicaid as Title XVIII and Title XIX of the Social Security Act. ${ }^{1}$ Shortly after, Medicare's "extended care benefit" began, offering Medicare beneficiaries skilled nursing facility (SNF) care after a qualifying stay of 3 or more consecutive inpatient midnights. ${ }^{2}$ Fifty years later, the word "inpatient" remains embedded in statute, limiting SNF coverage for Medicare beneficiaries hospitalized as outpatients under observation for part or all of a 3 -midnight stay. ${ }^{3}$

At the individual Medicare beneficiary level, the financial impact of this policy is clear. The Office of Inspector General (OIG) reported a $\$ 10,503$ beneficiary out-of-pocket cost per uncovered SNF stay following an observation hospitalization in 2012. ${ }^{4}$ But the actual number of Medicare beneficiaries impacted by this coverage gap is unknown. Using 2009 claims data, Feng et al..$^{5}$ estimated that 0.75\% of previously community dwelling Medicare beneficiaries are discharged to a SNF following an observation hospitalization, and the OIG reported 617,702 beneficiary hospital stays of 3 or more midnights not meeting the 3 -midnight inpatient requirement in 2012, with 4\% of these beneficiaries discharging to SNFs. ${ }^{4}$ Yet these studies based on Medicare claims data only capture actual SNF utilization, failing to answer the critical question: How many Medicare beneficiaries need, but forgo, SNF care following a non-qualifying observation hospital stay? In this issue of the Journal of Hospital Medicine, Goldstein et al. ${ }^{6}$ provide insight to that question. Using chart review of physical therapy and case management recommendations for post-acute SNF care, Goldstein et al. ${ }^{6}$ compare actual discharge rate to SNF or acute inpatient rehabilitation following an observation stay when such disposition is recommended. In their two-hospital system, fewer than $20 \%$ of previously community-dwelling hospitalist patients followed recommendation for post-acute facility stay after observation hospitalization, and more than $40 \%$ cited financial concerns as the reason for declining. Patients recommended for SNF also were more likely to be rehospi-

\footnotetext{
*Address for correspondence and reprint requests: Ann M. Sheehy, MD, MS, University of Wisconsin School of Medicine and Public Health, Department of Medicine, Division of Hospital Medicine, 1685 Highland Avenue, MFCB 3126 , Madison, WI 53705; Telephone, 608-262-2434; Fax: 608-265-1420; E-mail: asr@medicine.wisc.edu
}

Received: October 3, 2016; Accepted October 5, 2016

2017 Society of Hospital Medicine DOI 10.12788/jhm.2707 talized in the subsequent 30 days after discharge, confirming this as a vulnerable patient population. Given Medicare's original intent to improve health care access for seniors, the case for change seems clear, and the repercussions of not addressing the plight of patients hospitalized under observation is having negative financial and overall detrimental health impacts.

But there are other compelling reasons why this 50 -yearold law needs to be improved. Hospital care today is vastly different than when Medicare became law. Average hospital length of stay for patients 65 years and older was 14.2 days in $1965^{7}$ compared to 5.2 days today, ${ }^{8}$ clearly a shift in what 3 days of hospital care means. Most importantly, observation stays have become a major part of hospital care. Between 2006 and 2014, per-beneficiary outpatient visits (which include all observation stays) increased $44.2 \%$ nationally, while inpatient discharges decreased $19.9 \% .{ }^{9}$ In 2012, the Centers for Medicare \& Medicaid Services (CMS) received 1.7 million outpatient observation claims and an additional 700,000 inpatient claims that started with observation days. ${ }^{10} \mathrm{CMS}$ also expected the 2 -midnight rule to reduce outpatient observation stays, ${ }^{4}$ but a recent OIG report ${ }^{11}$ found that outpatient stays increased $8.1 \%$ in the first year (FY 2014) under the new rule, and there were still 748,337 long observation stays (those lasting 2 midnights or longer) in 2014 , only a small $(2.8 \%)$ decrease from the prior year. These factors limit Medicare beneficiary post-acute SNF eligibility in ways that could not have been anticipated when the extended care benefit was created to help seniors access needed health care.

Policymakers must consider cost when considering statutory change. Waiver programs in the 1980 s suspending the 3 -midnight requirement raised concerns over potential increase in both SNF utilization and associated costs. ${ }^{12}$ However, more recent data suggest that altering the 3-midnight requirement may not increase post-acute SNF utilization. From 2006 to 2010, Medicare Advantage programs that waived the 3-midnight requirement saw a decrease in hospital length of stay without increased SNF utilization or SNF length of stay, indicating that access to the right level of care at the right time could be cost-saving. ${ }^{13}$ Recent data from the Bundled Payments for Care Improvement (BPCI) program found savings were largely related to decreased SNF utilization when payments were episode-based, ${ }^{14}$ a trend that may continue as Medicare moves away from feefor-service towards bundled payments for more conditions. 
And although neither example directly tests changing the 3-midnight requirement to include observation midnights, both studies suggest that innovative health care delivery and modification of SNF access did not result in increased SNF utilization or greater post-acute costs. In fact, as Goldstein et $\mathrm{al} .{ }^{6}$ showed, patients recommended for post-acute SNF following observation stay were more likely to be rehospitalized within 30 days, an additional cost that could potentially be avoided if these patients had SNF access. We believe that these correlations strongly support rescinding the 3-midnight requirement, or at least amending it to allow nights spend under observation to count as "inpatient" for the purposes of SNF benefit coverage.

That being said, what can be done? In 2015, the Medicare Payment Advisory Commission (MedPAC) recommended changing the 3 -night requirement to require just one of 3 midnights to be inpatient to make a qualifying stay. ${ }^{10}$ Although an improvement over current law, this proposal would not help the majority of beneficiaries who are exclusively hospitalized under observation status. The "Improving Access to Medicare Coverage Act of 2015", to be reintroduced in Con-

\section{References}

1. Medicare \& Medicaid Milestones 1937-2015. https://www.cms.gov/AboutCMS/Agency-Information/History/Downloads/Medicare-and-Medicaid-Milestones-1937-2015.pdf . Accessed September 25, 2016.

2. Loewenstein R. Early effects of Medicare on the health care of the aged. https:// www.ssa.gov/policy/docs/ssb/v34n4/v34n4p3.pdf. Accessed September 25, 2016.

3. US Social Security Act, Sec. 1861 (i). [42 U.S.C. 1395x]. https://www.ssa.gov/ OP_Home/ssact/title18/1861.htm. Accessed September 25, 2016.

4. Department of Health and Human Services Office of Inspector General. Hospitals' use of observation stays and short inpatient stays for Medicare beneficiaries, OEI-02-12-00040. Available at: https://oig.hhs.gov/oei/reports/oei-02-12-00040. pdf. Accessed September 25, 2016.

5. Feng Z, Jung H-Y, Wright B, Mor V. The origin and disposition of Medicare observation stays. Med Care 2014;52:796-800.

6. Goldstein JN, Schwartz JS, McGraw P, Banks TL, Hicks LS. The unmet need for postacute rehabilitation among medicare observation patients: a single-center study. J Hosp Med. 2017;12(3):168-172.

7. Vital and Health Statistics. Trends in hospital utilization: United States, 1965-1986. https://www.cdc.gov/nchs/data/series/sr_13/sr13_101.pdf. Accessed September 25, 2016

8. Healthcare Cost and Utilization Project (HCUP). Statistical brief \#180. Overview of hospital stays in the United States, 2012. http://www.hcup-us.ahrq.gov/ reports/statbriefs/sb180-Hospitalizations-United-States-2012.pdf. Accessed September 25, 2016.

9. MedPAC March 2016 Report to the Congress. Chapter 3. Hospital inpatient and gress in the coming weeks, would count any midnight spent in the hospital towards the 3-midnight stay requirement, and has bipartisan, bicameral support and cosponsorship. ${ }^{15}$ In 2015, through unanimous bipartisan, bicameral support, Congress passed the NOTICE Act (PL 114-42), which requires hospitals to inform Medicare beneficiaries hospitalized under observation..$^{16}$ We believe that the data are clear to both sides of the aisle that Congress should now work together using scientifically-supported research to improve the exact observation policies they felt patients should be informed of. Passing the Improving Access to Medicare Coverage Act is the logical next step in this arena.

Medicare was intended to give seniors access to the healthcare they need. Growth in hospital-based observation care begs for modernization of the statutory 3 -inpatient midnight rule. Counting all midnights towards the 3 -midnight requirement, whether those midnights are outpatient observation or inpatient, is the right first step.

Disclosures: Representative Courtney is the bill sponsor of the Improving Access to Medicare Coverage Act. The authors report no other conflicts.

outpatient services. http:/www.medpac.gov/docs/default-source/reports/march2016-report-to-the-congress-medicare-payment-policy.pdf?sfvrsn=0. Accessed September 25, 2016.

10. MedPAC. June 2015 Report to the Congress. Chapter 7: Hospital shortstay policy issues. http://www.medpac.gov/docs/default-source/reports/ chapter-7-hospital-short-stay-policy-issues-june-2015-report-.pdf?sfvrsn $=0$ Accessed September 25, 2016.

11. Department of Health and Human Services Office of Inspector General. Vulnerabilities remain under Medicare's 2-midnight hospital policy, OEI-02-15-00020. https://oig.hhs.gov/oei/reports/oei-02-15-00020.pdf. Accessed February 19, 2017.

12. Lipsitz L. The 3-night hospital stay and Medicare coverage for skilled nursing care. JAMA. 2013;310: 1441-1442.

13. Grebela R, Keohane L Lee Y, Lipsitz L, Rahman M, Trevedi A. Waiving the threeday rule: admissions and length-of-stay at hospitals and skilled nursing facilities did not increase. Health Affairs. 2015;34:1324-1330.

14. Dummit L, Kahvecioglu D, Marrufo G, et al. Association between hospital participation in a Medicare bundled payment initiative and payments and quality outcomes for lower extremity joint replacement episodes. JAMA. 2016;316(12): $1267-1278$.

15. HR. 1571 Improving Access to Medicare Coverage Act of 2015. https://www.govtrack.us/congress/bills/114/hr1571/text. Accessed September 25, 2016.

16. PL 114-42. The NOTICE Act. https://www.govtrack.us/congress/bills/114/hr876. Accessed September 25, 2016. 